\title{
Health Care Transition of Adolescents and Young Adults with Haemophilia: the Situation in Germany and the Munich experience
}

\author{
Christoph Bidlingmaier ${ }^{1,2}$ Martin Olivieri ${ }^{2}$ Freimut \\ ${ }^{1}$ Centre for Development and Complex Chronic Diseases in Children \\ (iSPZ Hauner), Haemophilia Unit, LMU Munich, Munich, Germany \\ 2 Department of Paediatrics, Paediatric Haemophilia Centre, LMU \\ Munich, Munich, Germany \\ ${ }^{3}$ Children's Hospital, Kantonsspital Luzern, Lucerne, Switzerland \\ ${ }^{4}$ Department of Anaesthesiology, Ludwig-Maximilians University, \\ Munich, Germany \\ ${ }^{5}$ Department of Transfusion Medicine, Cell Therapeutics and \\ Haemostaseology, Ludwig-Maximilians University, Munich, Germany \\ Hämostaseologie 2020;40:97-104.
}

\author{
Address for correspondence Dr. med. Christoph Bidlingmaier, MD, \\ Centre for Development and Complex Chronic Diseases in Children \\ (iSPZ Hauner), Lindwurmstr. 4, 80337 Munich, Germany \\ (e-mail: christoph.bidlingmaier@med.uni-muenchen.de).
}

\begin{abstract}
Keywords

- haemophilia

- transition

- medical

- psychosocial
\end{abstract}

Zusammenfassung

Schlüsselwörter

- Hämophilie

- Transition

- medizinisch

- psychosozial
Patients suffering from haemophilia encounter various phases in life, in which individual needs, life situations, and self- and disease perception change rapidly. One of these phases spans from the beginning of puberty until early adulthood, in which individuals gain self-responsibility and reach independence and autonomy. In this challenging time that determines future health, adolescents and young adults need sustainable familiar and professional support. A change in health care team and treatment centre may expose adolescent patients to threats but also provides the possible opportunity to be well prepared. While there is emerging evidence that the socalled health care transition programmes are effective in maintaining quality of care in other disease areas, transition programmes for patients with haemophilia are still rare in Germany, and the evidence is limited. We describe the situation in Germany, discuss our experience in Munich and review some of the available guidance; we conclude that transition programmes should become a standard of care in haemophilia.

Patienten mit Hämophilie durchlaufen verschiedene Lebensabschnitte, in denen sich ihre Bedürfnisse, Lebensumstände und ihr Blick auf die Erkrankung und sich selbst verändern. Eine dieser Phasen umfasst die Pubertät und den Übergang ins Erwachsenenalter. In dieser Zeit erlangen die Patienten Eigenverantwortung und streben nach Unabhängigkeit und Autonomie. Diese Phase ist herausfordernd und bestimmend für die gesundheitliche Zukunft. Daher benötigen die Patienten eine tragfähige familiäre und professionelle Unterstützung, um Ängsten zu begegnen und mögliche Chancen herauszuarbeiten. Die Effektivität von Transitions-Programmen wird bereits für viele Krankheitsbilder in der Literatur beschrieben, allerdings werden diese im Bereich der Hämophilie in Deutschland selten angewendet. Wir beschreiben die Situation in Deutschland, erläutern unsere Münchner Erfahrungen und besprechen einige der verfügbaren Empfehlungen aus der Literatur. Zusammenfassend sollten Transitions-Program Teil der Routinebehandlung bei Hämophilie werden. received

July 29, 2019

accepted after revision

November 4, 2019 (c) 2020 Georg Thieme Verlag KG Stuttgart · New York
DOI https://doi.org/

$10.1055 / \mathrm{s}-0039-3402804$. ISSN 0720-9355. 


\section{Introduction}

Haemophilia is an inherited, lifelong bleeding disorder resulting from a deficiency of clotting factor VIII or IX. Due to its X-chromosomal inheritance pattern, males are almost exclusively affected, suffering from a markedly enhanced bleeding tendency correlated with the severity of the disease. While some patients show bleeding as early as in the neonatal period, most patients with severe haemophilia will present with an unusual haematoma as toddlers. Later, the bleeding pattern is correlated with the patient's mobility and activity. If joint bleeds occur, they might lead to joint damage and immobility as a sequela. The risk of bleeding affects the patient's everyday life, e.g. admission to and activity in kindergarten, school and sports activities. To allow a widely normal life while protecting joint health, prophylactic treatment with clotting factor concentrates ${ }^{1}$ has been employed as the standard of care. This treatment has led to a better quality of life in patients, and new alternative non-factor treatment strategies might even improve the situation.

\section{Transition in Chronically III Young People}

The time of puberty and adolescence represents a period of developmental tasks, vulnerability and opportunities, and is associated with medical, biological and emotional changes. Although not generally a time of great stress and fragility for all, ${ }^{2}$ young people might experience a high level of insecurity while reaching for autonomy and independence, building identity and gaining increasing amounts of responsibility.

For chronically ill adolescents and young adults (AYAs), all of the typical problems of teenagers apply, but the health status of ill juveniles is especially at risk - first, because of the stress imposed by the disease, leading to a higher vulnerability and a higher risk to develop psychosocial problems, ${ }^{3}$ and second, due to an often decreasing adherence to therapy or problems in self-management. Parents, peers and professional caregivers can help to guide patients through this process. ${ }^{4}$

The change of the medical treatment centre for AYAs with a chronic disease might be a risk but also a chance to ensure the future quality of treatment in these patients.

\section{Health Care Transition Programmes: Evidence and Guidelines}

Health care transition (HCT) programmes aim at reducing these potential dangers and improving quality of care by a holistic and structured education and guidance of the patients and their families. ${ }^{5-7}$

The Cochrane Study Group searched for studies and relevant reviews on the topic of transition ${ }^{8}$ and identified four randomized controlled trials that met the inclusion criteria, covering a limited range of interventions, ${ }^{9-12}$ but not including haemophilia. Although there was some evidence for a positive impact, the current studies' database was too limited to draw firm conclusions on the effectiveness of the evaluated interventions and the certainty of the body of evidence from these studies was low.
A recent and systematic literature review on this topic ${ }^{13}$ identified 43 (out of 3,844 articles) publications that met their evaluation criteria. Positive outcomes due to a structured transition approach comprised an improvement in adherence, improved perceived health status, quality of life and self-care skills plus increased adult visit attendance, and less time between the last paediatric visit and the initial adult visit.

However, due to the lack of detailed descriptions of transition interventions, it is still not possible to link specific transition interventions to outcomes. ${ }^{6,13}$

Despite this lack of randomized controlled trials and sometimes heterogeneous results, structured HCT programmes are internationally accepted as an important part of regular medical care, and various consensus statements and guidelines (e.g. diabetes, ${ }^{14}$ congenital heart disease ${ }^{15}$ or cystic fibrosis ${ }^{16}$ ) list similar core elements of these programmes.

Exemplarily, the American Academy of Pediatrics (AAP) recommendations define nine principles of $\mathrm{HCT}^{6}{ }^{6}$ which mainly focus on recognizing the AYA patient as a newly self-responsible person and providing knowledge and tools to support these individuals in caring for themselves: (1) focus on the young individual, (2) emphasis on self-responsibility but also the possible support, (3) acknowledgment of the patient's individuality, personal strengths and differences, (4) recognition of the special needs of this age group, (5) an early HCT start that continues into young adulthood, (6) shared responsibility of paediatric and adult caregivers, (7) consideration of cultural beliefs and socioeconomic status, (8) necessity to achieve health care equity and (9) support of parents and caregivers to build up the patient's knowledge and decision-making capacity. It is also important to acknowledge that the chronic disease affects not only the patient but also his parents and siblings, i.e. the family system as a whole, ${ }^{17}$ and that, for example, parental anxiety might even interfere with the transition process. ${ }^{18}$

In conclusion, HCT programmes are an area of increasing interest and importance, ${ }^{19}$ despite the lack of evidence from randomized controlled trials. ${ }^{7}$

\section{Transition in Adolescents and Young Adults with Haemophilia}

We conducted a PubMed search for 'transition' AND 'haemophilia OR hemophilia' AND 'randomised OR randomized' but identified no documents that matched the search terms. Replacing 'randomised OR randomized' by 'studies' we found 44 documents, most of them not focusing on specific HCT programmes for patients with haemophilia but on the age group in general (e.g. Valentino et $\mathrm{al}^{20}$ ), treatment adherence (e.g. Schrijvers et $\mathrm{al}^{21}$ ), caregiver impact, ${ }^{22}$ and possible studies $^{23}$ and outcome indicators of HCT programmes. ${ }^{24}$

However, these studies together with the above-reviewed experience in HCT from other disease areas support the need for education and transition programmes, joint paediatric/ adult clinics, and special youth and transition clinics. ${ }^{25}$

As outlined above, the medical and therapeutic life of a patient with haemophilia is a life in transition from birth to 
adulthood concerning mobility, disease activity, therapy, social life and perception. ${ }^{25}$ As in other chronic diseases, families and patients benefit from health care support during this process, allowing optimal preparation and advice. ${ }^{26}$

Therefore, the 'National Hemophilia Foundation of the United States' implemented transition guidelines in 2003, ${ }^{27}$ quoting the work of Mary C. Paone in stating that 'The goal of transition is to provide health care that is uninterrupted, coordinated, developmentally appropriate and psychologically sound prior to and throughout transfer into the adult system'. ${ }^{28}$ The relevance of this goal has been underlined by an early study, showing that the stress level of patients with haemophilia is higher and the quality of life is lower in the post-transition era. ${ }^{29}$

\section{Medical Aspects of Transition in Patients with Haemophilia}

When discussing the coming life changes and the problems faced by our patients, multiple questions and key problems are raised; medical, psychosocial and legal aspects are involved.

It is crucial that patients with haemophilia understand their medical condition, possible barriers and treatment options available. At this age, patients should be able to perform home treatment by themselves and to act in the case of bleeding. This skill and the swap from parent care to self-care are the key to independence ${ }^{29}$; e.g. to allow studying abroad, patients must be able to substitute factor concentrates at work or while travelling. Patients also need to know about complications during their course of disease, possible physical impairments and pain management in patients who already have affected joints and consecutive arthrosis.

At a time with increasing numbers of alternative treatment options arising, only educated patients will be able to judge their current treatment and to decide whether they are willing to change treatment or enter clinical trials, which are far more often available to adult patients than to children. There is evidence that taking into account AYA needs and preferences when planning treatment enhances adherence to prophylactic treatment. ${ }^{30}$ Patients often do not consider themselves to be 'ill' as they have few limitations in life. This good outcome is often the result of successful therapy, and patients might not be aware that further treatment adherence is necessary to maintain a good medical status. ${ }^{31}$

\section{Psychosocial Aspects of Health Care Transition in Haemophilia}

Several psychosocial aspects affected by the diagnosis of haemophilia have been described. ${ }^{32}$ As in healthy children, peer acceptance is very important. This includes the possibility of sharing the diagnosis with friends. AYAs with haemophilia aim for the perception of being normal. For some, activities such as youth camps provide relief, allowing them to pair up with AYAs with the same problems. Regarding the coming changes of care, young patients are often unsure about adult care. ${ }^{33}$ Many have known their paediatric haemophilia centre since birth and have now to face new doctors. A gradual transfer of responsibilities, both in medical care and in selfcare (in comparison to being looked after by parents), will improve outcome. ${ }^{24}$ Additionally, the change from school to university or work raises many questions. What job to choose, where to live and how to care for oneself are all questions that are also asked by healthy adolescents; however, these questions are strongly influenced by the imposed and perceived barriers in AYAs with haemophilia. Some guidance might be found on web sites that focus on jobs and haemophilia, e.g. www.berufe-haemophilie.de. ${ }^{34}$ Additionally, many questions around the 'disabled person' status arise. The identification of disabled persons and the laws regulating the compensation for those with disabilities could be seen as a benefit, but it also imposes fear on AYAs because some employers might hesitate to employ a person with haemophilia. Therefore, social law counselling and job interview training are a necessary part of the HCT. Being abroad, travelling the world and taking a year off are common wishes of AYAs after finishing school; again, attaining these goals might be influenced by haemophilia. ${ }^{35}$ Finally, partnership and sexuality are issues that are rarely discussed during a regular consultation but have a great impact on our patients. ${ }^{36}$

\section{The Situation for Transition in Patients with Haemophilia in Germany}

In 2015, the 'Standing Commission Paediatrics' of the German Society of Thrombosis and Haemostasis Research (Gesellschaft für Thrombose und Hämostaseforschung, GTH e.V.) initiated a survey amongst its members to examine the current status and availability of HCT programmes in haemophilia care in Germany. ${ }^{37}$ Out of 45 member centres in Germany, 33 responded (73\%), 13 of these fulfilled the criteria of a comprehensive care centre, 15 were haemophilia treatment units (Hämophilie Behandlungseinheiten, HBE) and 5 were smaller haemophilia units (Hämophilie Behandler, HB). Fifteen centres were specialized paediatric haemophilia centres, and 18 centres treated both children and adults. A regular transition program was in place in only four centres (13\%). At least one joint clinic with paediatric and adult physicians was held in nine centres (27\%). Sixteen centres (48\%) reported that they do accompany the transition, but not in a standardized manner; in four centres (12\%), no options for transition assistance were available. Interestingly, these findings were not correlated with the type or size of the treatment centres. This short survey showed, impressively, that, despite their long-accepted relevance, transition programmes for haemophilia treatment in Germany were still rare and less coordinated than in other countries or in other disease areas as of 2015.

\section{Experience from Munich}

Although working closely together, both the paediatric and adult haemophilia treatment centres of the University of Munich are independent. Children are treated only by paediatricians in the children's hospital.

Until 2010, AYAs with haemophilia were referred rather randomly from the paediatric haemophilia centre, Munich, 
to the adult centre. In many cases, patients were just released to the adult department with a discharge summary. Some patients were treated in the paediatric centre until their late 20 s, illustrating both the wish of the patients and, sometimes especially, their parents, for continuity in health care providers; in addition, the paediatricians sometimes have difficulty letting go of 'their' patients, a phenomenon previously described in a position paper of the Society for Adolescent Medicine in $1993 .^{18}$

New regulations by insurance companies and a new hospital policy in Munich driven by limited resources have led to a stricter referral of patients to the adult department on their 18th birthday since 2010. Although it is not required by law to transfer adult patients for outpatient visits to the adult department, this transfer was necessary e.g., for practical reasons to ensure adequate inpatient care when needed, since adult patients with haemophilia were no longer allowed admission to our paediatric hospital.

However, although this upcoming event was discussed on some paediatric centre visits, the process of leaving paediatric care raised anxiety in both patients and parents, since they felt inappropriately prepared for this change.

To ease this rather abrupt change and to optimize the transfer of medical information, patients are often accompanied by one of their well-known paediatricians for their first visit to the adult department. However, this one joint paediatric and adult clinic fulfils merely the basic criteria of a structured, adequate HCT program.

\section{Starting a Structured Transition Program in Munich}

Therefore, together with our colleagues from the adult department, we aim to optimize the transition process and have started a transition program in 2019. Instead of just one joint paediatric/adult clinic, the program consists of several visits, begins with puberty and spans into early adulthood, as recommended by most authors in the field (e.g. White and Cooley $^{6}$ ). However, there is no fixed age, as the right time for transition always depends on the individual situation of the patient. $^{26}$

From January to September 2019, three patients were enrolled in the structured HCT program, with two transition appointments (see - Table 1 ) by now. Five patients aged 16 years and older have participated in a shortened program, where we have provided information on the disease, independence, social law and career choice during one to three additional appointments. Although our program is at its start and has not been evaluated yet, the feedback from both patients with haemophilia and caregivers was positive. For the future we plan to offer the structured HCT program to all our patients.

As a first step, the parents are asked to leave the room for some time during the appointment when the patients are approximately 14 years of age. This happens often during the physical examination by the paediatrician and the physiotherapist, allowing some privacy for the patient and giving room for a trustful talk between the patient and his profes- sional caregivers. At the next appointment, a first transition appointment is scheduled with the patient, his parents, the physician and a social worker. Until the actual transition, transition issues are always part of the regular appointments. According to the needs and preferences of the patient, these discussions will be private or together with the parents or other health care providers.

To ensure a holistic approach, we now use the documentation tool shown in -Table 1. Similar documents have been developed at the Ludwig Maximilian University (LMU) Centre for Development and Complex Chronic Diseases in Children (iSPZ Hauner) by the divisions of rheumatology, gastroenterology and diabetes and are in regular use for the transition of their patients. Studies using this tool are ongoing at the iSPZ Hauner, but no data have yet been published.

Common barriers during the HCT have been described. ${ }^{33}$ In -Table 2, we show how we attempt to conquer these barriers in the transition process of young people with haemophilia. Since the transition reaches from paediatric to adult care, the key element to overcome these barriers is a close and visible collaboration between paediatric and adult haemophilia caregivers and, if possible, to allow patients to experience the regional haemophilia caregivers as a team. Of course, a joint haemophilia centre for both paediatric and adult patients assembling the individual expertise of specialized physicians would probably help to overcome bureaucratic barriers.

\section{Further Information to Start a Structured Transition Process}

The American Society of Hematology has created a 'Haemophilia Transition Readiness Assessment Template', consisting of both a self-assessment completed by the AYA and a medical assessment and epicrisis completed by the physician. ${ }^{38}$ This tool, covering disease knowledge, medication management, insurance and privacy issues but also the level of confidence of the patients to cope with their disease, is very helpful in determining areas of special needs for each individual prior to transition.

The web site 'got transition' (www.gottransition.org) offers many resources, focusing on the 'Six Core Elements of Health Care Transition', which are as follows: (1) installing a transition policy; (2) tracking and monitoring transition; (3) evaluating readiness for transition; (4) planning transition; (5) transferring of care and (6) completing the transition. Available in English and Spanish, this web site offers many suggestions on how to implement a transition program.

More ideas on how to support youth with chronic diseases can be found in an article from members of the very active 'transition' working group of the German Society of Rheumatology. ${ }^{39}$ Although focused on AYAs with rheumatic disease, many of the proposed services could be adopted for patients with haemophilia.

More information reflecting the situation in Germany can also be found on the web site of the German Society of Transition Medicine (Gesellschaft für Transitionsmedizin, GfTM e.V., www.transitionsmedizin.net). 
Table 1 Pathway, topics and documentation for the transition of AYAs with haemophilia at Munich Haemophilia Centre

First discussion with adolescents and parents (paediatrician, clinical psychologist, social worker)

Aim of transition process = self-responsibility and autonomy in disease-related aspects

Evaluation and acknowledgment of parent's efforts and accomplishments

Autonomy, self-responsibility

Topics to discuss (i.e. medical knowledge, therapy, education/job, transition to adult caregivers)

From next appointment: start alone, parents join later

Medical knowledge (paediatrician)

Diagnosis

Comorbidities, infectious diseases

Orthopaedic problems, sports, sport injuries

Genetics of the disease, family history

Course of the disease, acute and chronic complications, sequelae

$\square$ Medication: name, dose, frequency, home self-therapy, mechanism of action, prior drugs, complication, further developments

$\square$ Emergencies, emergency treatment

Laboratory values

Sexuality, genetics

Vaccinations: route of administration, risks, missing vaccinations

Alcohol, smoking, drugs

Changing treatment teams (paediatrician, clinical psychologist, social worker)

Process of appointment: history, questions, examination, prescriptions

Differences in adult treatment: time, self-responsibility, expectations, medication, examinations

Medical letter, doctor's wording

Finding a new physician, expectations, how to deal with disappointment

Coping with the disease (clinical psychologist)

Autonomy, self-responsibility

Successful home self-therapy? Barriers?

Self-perception of being chronically ill. Blame? Guilt?

Peer group, friends, best friends, family

Social system: caregivers, attachment figures

Information: instruction leaflet, NGOs, patient initiatives, internet resources

Hobbies, sports

Dealing with social pressure

Dealing with alcohol, drugs

Sexuality and partnership

Social law (social worker)

Moving, travel, working and studying abroad

School, university or job, choosing a job

Insurance, additional costs, additional treatments

Disability ID, disability compensation, case of hardship, social law, employment law

Disease-specific problems

Complete transition (paediatrician, adult physician, social worker, clinical psychologist)

$\square$ Decision on new treatment centre

Next appointment in adult treatment centre

Prepare discharge summary and discuss with patient

Contact adult physician

Confirm joint clinic with adult physician

Hold joint clinic in adult treatment centre

Ensure delivery of new emergency card, emergency numbers

Abbreviations: AYAs, adolescents and young adults; NGOs, non-governmental organizations.

\section{Future Outlook}

HCT programmes are also there in the field of vision for health care politicians and cost payers. Several German insurance companies have started transition programmes together with the German professional organization of paediatricians (Berufsverband der Kinder und Jugendärzte, BVKJ e.V., www.bvkj. de). Although none of these programmes currently include haemophilia, some programmes plan to widen the list of indications in the near future. These programmes focus on medical practitioners, but they are the first in Germany to actually address the issue of public reimbursement of transition programmes, which might help haemophilia centres while discussing costs with insurance companies.

Of course, HCT programmes should be monitored and regularly evaluated. The French haemophilia network has 
Table 2 The most commonly reported barriers to successful transition as reported in Gray et al ${ }^{33}$ and the solutions already in place or planned at Munich Haemophilia Centre

\begin{tabular}{|c|c|}
\hline Barrier & Solutions at Munich Haemophilia Centre \\
\hline $\begin{array}{l}\text { Relationships between patient, } \\
\text { paediatrician and paediatric team }\end{array}$ & $\begin{array}{l}\text { - Joint clinic with adult team } \\
\text { - Joint patient activities for children, adolescents, adults and parents }\end{array}$ \\
\hline Beliefs/expectations & $\begin{array}{l}\text { - Structured transition plan } \\
\text { - Connect to young adults with haemophilia who have already finished } \\
\text { the process of transition } \\
\text { - That is, summer camp ('Chiemseefreizeit' of the German Haemophilia Society } \\
\text { [Deutsche Hämophilie Gesellschaft, DHG e.V.]) } \\
\text { - AYA visits to parent-patient weekends of the Bavarian advisory service for } \\
\text { people with bleeding disorders (Bluter Beratung Bayern, BBB e.V.) } \\
\text { - Tour through adult clinic }\end{array}$ \\
\hline Skills/efficacy & $\begin{array}{l}\text { - Start transition early and regularly } \\
\text { - Provide education and training (related to medical and therapeutic topics } \\
\text { as well as social law) } \\
\text { - Provide training on self-management, home treatment and dealing } \\
\text { with emergencies } \\
\text { - Encourage independent visits or visits where at least some time is spent } \\
\text { without parents } \\
\text { - Use of new technologies to involve adolescents in their treatment, } \\
\text { such as electronic diaries or tools to calculate individual pharmacokinetics } \\
\text { - Regular evaluation of transition readiness } \\
\text { - Close collaboration between teams }\end{array}$ \\
\hline Access & $\begin{array}{l}\text { - Transition specialist (social worker) } \\
\text { - Use of biopsychosocial resources of the iSPZ Hauner }\end{array}$ \\
\hline
\end{tabular}

Abbreviations: AYA, adolescents and young adults.

addressed the issue of HCT in patients with haemophilia and initiated a prospective study to elucidate the haemophilia transition (TRANSHEMO, ClinicalTrials.gov Identifier: NCT02866526). The study aims for results by December 2019 and will hopefully add evidence to the sparse knowledge on HCT in patients with haemophilia. ${ }^{23}$

For AYAs with malignant and haematological diseases, the 'Working Group on Adolescents, Young Adults, and Transition (Arbeitsgemeinschaft Adoleszenten, junge Erwachsene, Transition, AjET)' has been established within the Society for Paediatric Oncology and Haematology (GPOH). This group intends to build a national, multidisciplinary network to increase awareness of the topic and to define and evaluate standards of care. Some members of this group will focus on AYAs with inherited bleeding disorders. ${ }^{40}$

\section{Conclusion}

In conclusion, a structured HCT program has been shown to be effective for AYAs in many disease areas. Although there is not yet much evidence in haemophilia, it seems clear that adequate planning and a program providing education and a structured transition will improve medical care and outcomes. We hope that, by these joint efforts of paediatric and adult caregivers, this important step in independence and self-responsibility will be comfortable and successful for our patients. While the Munich HCT program has just started and has not been evaluated by now, material such as the provided documentation tool might be of interest for other centres. We conclude that structured transition programmes for
AYAs should become part of the standard of care for patients with haemophilia.

\section{Conflicts of Interest}

Dr. Bidlingmaier reports personal fees from Biotest, personal fees from CSL Bering, personal fees from Novo Nordisk, other from Roche, personal fees from Bayer, personal fees from Sobi, personal fees from Shire, outside the submitted work; Dr. Bidlingmaier is PI of the German Paediatric Haemophilia Research Database. GEPHARD receives funding from Bayer, Biotest, CSL Behring, Intersero, Octapharma, Sobi, Pfizer, Shire/Takeda, Grifols and Novo Nordisk.

Dr. Olivieri reports personal fees from Sobi, personal fees from Pfizer, personal fees from Biotest, personal fees from Takeda, personal fees from Bayer, personal fees from Novo Nordisk, grants and personal fees from CSL Behring, personal fees from Octapharma, personal fees from Grifols, outside the submitted work.

Dr. Kurnik reports grants and personal fees from Bayer, personal fees from Biotest, personal fees from CSL Behring, personal fees from Novo Nordisk, personal fees from Roche, personal fees from Sobi, personal fees from Shire/Takeda, outside the submitted work.

\section{Acknowledgments}

We wish to thank Petra Manzey, qualified social education worker and transition specialist, Stephanie Lardschneider, physiotherapist and Michaela Pfeifer, clinical psychologist, at the LMU Centre for Development and 
Complex Chronic Diseases in Children (iSPZ Hauner) for their work with our patients and most valuable advice during the transition process. We also thank our colleagues from rheumatology (Susanne Schalm, MD), gastroenterology (Kathrin Krohn, MD) and diabetes care (Susanne Bechtold-Dalla Pozza, MD), who initiated specific HCT programmes at the iSPZ Hauner in first place and generously shared their experience. For the revised version of this manuscript we gained editorial support from Dr. Mathias Jürs Medical Consulting, Frankfurt am Main, Germany.

\section{References}

1 Srivastava A, Brewer AK, Mauser-Bunschoten EP, et al; Treatment Guidelines Working Group on Behalf of The World Federation Of Hemophilia. Guidelines for the management of hemophilia. Haemophilia 2013;19(01):e1-e47

2 Remschmidt H. Psychosocial milestones in normal puberty and adolescence. Horm Res 1994;41(Suppl 2):19-29

3 Holder MK, Blaustein JD. Puberty and adolescence as a time of vulnerability to stressors that alter neurobehavioral processes. Front Neuroendocrinol 2014;35(01):89-110

4 Sawyer S, Drew S, Duncan R. Adolescents with chronic diseasethe double whammy. Aust Fam Physician 2007;36(08):622-627

5 Crowley R, Wolfe I, Lock K, McKee M. Improving the transition between paediatric and adult healthcare: a systematic review. Arch Dis Child 2011;96(06):548-553

6 White PH, Cooley WC; TRANSITIONS CLINICAL REPORT AUTHORING GROUP; AMERICAN ACADEMY OF PEDIATRICS; AMERICAN ACADEMY OF FAMILY PHYSICIANS; AMERICAN COLLEGE OF PHYSICIANS. Supporting the health care transition from adolescence to adulthood in the medical home. Pediatrics 2018;142 (05):e20182587

7 Wright C, Steinway C, Jan S. The genesis of systems of care for transition to adulthood services: emerging models in primary and subspecialty care. Curr Opin Pediatr 2018;30(02):303-310

8 Campbell F, Biggs K, Aldiss SK, et al. Transition of care for adolescents from paediatric services to adult health services. Cochrane Database Syst Rev 2016;4:CD009794

9 Betz CL, Smith K, Macias K. Testing the transition preparation training program: a randomized controlled trial. Intl J Child Adolesc Health 2010;3(04):595-607

10 Huang JS, Terrones L, Tompane T, et al. Preparing adolescents with chronic disease for transition to adult care: a technology program. Pediatrics 2014;133(06):e1639-e1646

11 Mackie AS, Islam S, Magill-Evans J, et al. Healthcare transition for youth with heart disease: a clinical trial. Heart 2014;100(14): 1113-1118

12 Steinbeck KS, Shrewsbury VA, Harvey V, et al. A pilot randomized controlled trial of a post-discharge program to support emerging adults with type 1 diabetes mellitus transition from pediatric to adult care. Pediatr Diabetes 2015;16(08):634-639

13 Gabriel P, McManus M, Rogers K, White P. Outcome evidence for structured pediatric to adult health care transition interventions: a systematic review. J Pediatr 2017;188:263.e15-269.e15

14 Nakhla M, Bell LE, Wafa S, Dasgupta K. Improving the transition from pediatric to adult diabetes care: the pediatric care provider's perspective in Quebec, Canada. BMJ Open Diabetes Res Care 2017; 5(01):e000390

15 Sable C, Foster E, Uzark K, et al; American Heart Association Congenital Heart Defects Committee of the Council on Cardiovascular Disease in the Young, Council on Cardiovascular Nursing, Council on Clinical Cardiology, and Council on Peripheral Vascular Disease. Best practices in managing transition to adulthood for adolescents with congenital heart disease: the transition process and medical and psychosocial issues: a scientific statement from the American Heart Association. Circulation 2011;123(13): 1454-1485

16 Al-Yateem N. Guidelines for the transition from child to adult cystic fibrosis care. Nurs Child Young People 2013;25(05):29-34

17 Waldboth V, Patch C, Mahrer-Imhof R, Metcalfe A. Living a normal life in an extraordinary way: a systematic review investigating experiences of families of young people's transition into adulthood when affected by a genetic and chronic childhood condition. Int J Nurs Stud 2016;62:44-59

18 Blum RW, Garell D, Hodgman $\mathrm{CH}$, et al. Transition from childcentered to adult health-care systems for adolescents with chronic conditions. A position paper of the Society for Adolescent Medicine. J Adolesc Health 1993;14(07):570-576

19 Pape L, Oldhafer M. Transition - the next step. J Transition Med 2019;1(01): Doi: 10.1515/jtm-2017-0001

20 Valentino LA, Santagostino E, Blanchette V, van den Berg M. Managing the pediatric patient and the adolescent/adult transition. Semin Thromb Hemost 2006;32(Suppl 2):28-31

21 Schrijvers L, Beijlevelt-Van der Zande M, Peters M, et al. Achieving self-management of prophylactic treatment in adolescents: the case of haemophilia. Patient Educ Couns 2016;99(07): 1179-1183

22 Schwartz CE, Zhang J, Su J. Longitudinal validity of the hemophilia caregiver impact measure. Qual Life Res 2019;28(07):1979-1987

23 Resseguier N, Rosso-Delsemme N, Beltran Anzola A, et al. Determinants of adherence and consequences of the transition from adolescence to adulthood among young people with severe haemophilia (TRANSHEMO): study protocol for a multicentric French national observational cross-sectional study. BMJ Open 2018;8(07):e022409

24 Sun HL, Breakey VR, Straatman L, Wu JK, Jackson S. Outcomes indicators and processes in transitional care in adolescents with haemophilia: a Delphi survey of Canadian haemophilia care providers. Haemophilia 2019;25(02):296-305

25 Young G. From boy to man: recommendations for the transition process in haemophilia. Haemophilia 2012;18(Suppl 5):27-32

26 Brand B, Dunn S, Kulkarni R. Challenges in the management of haemophilia on transition from adolescence to adulthood. Eur J Haematol 2015;95(Suppl 81):30-35

27 Belling L, Harrop M, Kocik S, et al. MASAC Document \#147: Transition Guidelines for People with Bleeding Disorders. Available at: https://www.hemophilia.org/Researchers-Healthcare-Providers/ Medical-and-Scientific-Advisory-Council-MASAC/MASAC-Recommendations/Transition-Guidelines-for-People-with-Bleeding-Disorders. Published 2003. Accessed October 4, 2019

28 Paone MC, Wigle M, Saewyc E. The ON TRAC model for transitional care of adolescents. Prog Transplant 2006;16(04):291-302

29 Bérubé S, Mouillard F, Amesse C, Sultan S. Motivational techniques to improve self-care in hemophilia: the need to support autonomy in children. BMC Pediatr 2016;16:4

30 Lee Mortensen G, Strand AM, Almén L. Adherence to prophylactic haemophilic treatment in young patients transitioning to adult care: a qualitative review. Haemophilia 2018;24(06):862-872

31 Lindvall K, Colstrup L, Wollter IM, et al. Compliance with treatment and understanding of own disease in patients with severe and moderate haemophilia. Haemophilia 2006;12(01):47-51

32 Sterling LE, Nyhof-Young J, Blanchette V, Breakey VR. Growing up with hemophilia: assessing teen's experiences and needs during transition to adult care. UTMJ 2013;90(04):149-154

33 Gray WN, Schaefer MR, Resmini-Rawlinson A, Wagoner ST. Barriers to transition from pediatric to adult care: a systematic review. J Pediatr Psychol 2018;43(05):488-502

34 Girisch M, Bidlingmaier C. Berufsberatung Hämophilie. Available at: https://www.berufe-haemophilie.de. Published 2010. Accessed October 4, 2019

35 Ringwald J, Rudolph P, Biner M, et al. Travel behaviour of patients with haemophilia. Travel Med Infect Dis 2013;11(03):159-165 
104 Health Care Transition of AYAs with Haemophilia Bidlingmaier et al.

36 Parish KL. Sexuality and haemophilia: connections across the lifespan. Haemophilia 2002;8(03):353-359

37 Schilling FH. Transition bei angeborenen Gerinnungsstörungen. Jahrestagung der Gesellschaft für Thrombose- und Hämostaseforschung e.V. Münster; 2016

38 American Society of Hematology. Hemophilia transition readiness assessment template. Available at: https://www.hematology.org/ Clinicians/Priorities/Transitions/5575.aspx. Last downloaded October 4, 2019
39 Schalm S, Niewerth M, Minden K. New support services for the care of young patients with rheumatic diseases [in German]. Z Rheumatol 2018;77(08):685-693

40 Escherich G, Bielack S, Maier S, et al. Building a national framework for adolescent and young adult hematology and oncology and transition from pediatric to adult care: report of the inaugural meeting of the "AjET" Working Group of the German Society for Pediatric Oncology and Hematology. J Adolesc Young Adult Oncol 2017;6(02):194-199 